Revue internationale de l'économie sociale

Recma

\title{
Associations, fondations et coopératives entre économie et
} société

\section{Jean-François Draperi}

Numéro 297, juillet 2005

URI : https://id.erudit.org/iderudit/1021846ar

DOI : https://doi.org/10.7202/1021846ar

Aller au sommaire du numéro

Éditeur(s)

Institut de l'économie sociale (IES)

ISSN

1626-1682 (imprimé)

2261-2599 (numérique)

Découvrir la revue

Citer ce document

Draperi, J.-F. (2005). Associations, fondations et coopératives entre économie et société. Revue internationale de l'économie sociale, (297), 4-4.

https://doi.org/10.7202/1021846ar d'utilisation que vous pouvez consulter en ligne.

https://apropos.erudit.org/fr/usagers/politique-dutilisation/ 


\section{ASSOCIATIONS, FONDATIONS ET COOPÉRATIVES \\ ENTRE ÉCONOMIE ET SOCIÉTÉ}

nitiée par des groupements de personnes, l'entreprise d'économie sociale est un fait social. Produisant des services et des richesses, elle est un fait économique. La conjugaison de ces deux dimensions, inévitable et complexe, est au cœur de ce numéro 297 dont les trois premiers articles sont issus des contributions au XIX ${ }^{\mathrm{e}}$ colloque de l'Addes.

Constatant la multiplication des relations entre acteurs marchands et acteurs non marchands à partir de la notion d'activité économique, Colas Amblard s'interroge sur les conditions dans lesquelles se nouent les partenariats entre l'association et l'entreprise commerciale. Il observe à ce propos un double déplacement, celui de l'association vers l'activité économique et celui de l'entreprise commerciale vers la « responsabilité sociale », et s'interroge sur ce qui peut permettre d'éviter l'instrumentalisation de l'une par l'autre.

Dominique Lemaistre et Odile de Laurens présentent les résultats de la première enquête nationale quantitative sur les fondations françaises. L'étude comprend deux parties: la première, sur la situation juridique et historique des fondations en France, permet de cerner les enjeux essentiels dans lesquels s'inscrit l'enquête; la seconde présente et analyse les principaux résultats, qui témoignent, grâce à une comparaison européenne, de la relative modestie du secteur des fondations en France. La richesse des résultats exposés devrait susciter des vocations pour des études novatrices sur les fondations, sur les liens entre fondations et entreprises ou sur l'intégration des fondations dans l'économie sociale.

A partir d'une volumineuse collecte de données quantitatives et qualitatives sur les opérations d'internationalisation des coopératives agricoles, René Mauget montre qu'en dépit de leur internationalisation, celles-ci continuent de jouer un rôle à la fois original et essentiel en faveur du maintien d'activités sur les territoires. Selon l'auteur, les coopératives agricoles seront demain plus encore qu'hier déterminantes face aux risques de délocalisation quaccroît la poursuite de la mondialisation des marchés.

Muriel Tabariés et Viviane Tchernonog analysent la participation des femmes à la vie et à l'administration des associations. Elles s'attachent particulièrement à la composition mixte ou non mixte des bureaux. Que ce soit sous l'angle des genres, des catégories socioprofessionnelles ou des générations, les groupes d'élus sont fréquemment assez homogènes. Ce fait et bien d'autres ouvrent des possibilités d'études plus qualitatives qui permettront, par exemple, de mieux comprendre les conditions d'accession des femmes à la présidence des associations. Enfin, Elie Alfandari et Bernard Piot approfondissent la relation entre le droit coopératif français et le droit européen de la SCE, relation sur laquelle nous serons nécessairement amenés à revenir dans les prochaines années. Avant de lire cette contribution, nous suggérons au lecteur de prendre connaissance de la note (en rubrique "Actualité ») de Caroline Naett, qui fait le point sur les derniers événements européens touchant à l'entrée en vigueur de la SCE, prévue avant la date limite du 18 août 2006.

Jean-François Draperi 